\title{
Development and validation of the moon phases concept inventory for middle school
}

\author{
Pierre Chastenay ${ }^{*}$ \\ Département de didactique, Université du Québec à Montréal, \\ CP 8888, succursale Centre-ville, Montréal, Québec H3C 3P8, Canada \\ Martin Riopel『 \\ Département de didactique, Université du Québec à Montréal, \\ CP 8888, succursale Centre-ville, Montréal, Québec H3C 3P8, Canada
}

(Received 24 February 2020; accepted 4 June 2020; published 29 July 2020)

\begin{abstract}
We present the development and validation of a new assessment tool, the Moon Phases Concept Inventory for Middle School (MPCI-MS), a concept inventory about the phases of the moon targeting students aged 10 to 14 years old. Items in the questionnaire are based on a careful examination of the concept domain of phases of the moon, ideas and concepts necessary to understand the mechanism of lunar phases, as chosen by a panel of seven professional astronomers. Questions and multiple-choice answers were tested for readability with 5 th grade students, tested for reading level, and submitted to a second panel of professional astronomers to check for face and construct validity of the items. The MPCI-MS was tested with $N=296$ students from grade 5 in elementary school to secondary 2 ( $M_{\text {age }}=10.2$ to 14.1 ). One item about global perspective on lunar phases had to be removed because of poor psychometric properties. The revised MPCI-MS has a post-test Cronbach alpha score of 0.786 and good overall psychometric properties: the mean difficulty index for the MPCI-MS pretest is 0.47 , and 0.61 for the post-test; mean point-biserial correlation (post-test) is 0.376 . Test-retest without instruction at one-week interval showed high test-retest reliability $\left[M_{\text {pre }}=13.696, M_{\text {post }}=14.523 ; t(45)=1.315, p=0.192\right]$. We conclude that the MPCI-MS is a reliable and valid instrument that can discriminate between novices and experts, and can be used to assess 10 to 14 year-old students' learning gains on the topic of lunar phases. The final version of MPCI-MS is a 19-item instrument, including two new questions about eclipses, that takes between 15 and 25 min for students to complete.
\end{abstract}

DOI: 10.1103/PhysRevPhysEducRes.16.020107

\section{INTRODUCTION}

Assessment is an integral part of teaching at any level, whether to reveal misconceptions present among students, to measure students' performance before and after a teaching intervention or to compare the effectiveness of different teaching strategies. Most assessment tools used in teaching and research are a type of tests known as concept inventories, designed to determine the "amount" of knowledge a student possesses at one point in time about a specific set of concepts. Concept inventories usually are criterion referenced, composed of multiple-choice questions with only one correct answer per question, and a series of distractors which are incorrect or irrelevant

\footnotetext{
*To whom all correspondence should be addressed. chastenay.pierre@uqam.ca

Published by the American Physical Society under the terms of the Creative Commons Attribution 4.0 International license. Further distribution of this work must maintain attribution to the author(s) and the published article's title, journal citation, and DOI.
}

answers often based on students' commonly held misconceptions [1]. Ideally, a student's score on a concept inventory will reflect the amount of content knowledge this individual has learned. Contrary to a norm-referenced test (i.e., a personality questionnaire), the goal of a concept inventory is to ascertain whether a respondent has mastered a predetermined amount of content knowledge about a specific topic.

This paper presents the development and validation of a concept inventory instrument about the phases of the moon intended for students aged 10 to 14 years old. The rationale behind this choice of topic and age group is the fact that the concept of lunar phases is present in the curriculum, at the end of elementary (middle school) and the beginning of high school, in most jurisdictions in Canada [2], in the United States [3,4], and in many member countries of the Organization for Economic Co-operation and Development (OECD) [5]. This means there is a real need for an assessment tool that can be used to measure knowledge possessed by students of that age group about lunar phases.

Unfortunately, assessment tools tailored to the topic to be taught, and which are appropriate for specific age groups, 
TABLE I. Currently available assessment tools about earth science, astronomy, and/or lunar phases. Instruments targeting students 10 to 14 years old are set to bold.

\begin{tabular}{lcc}
\hline \hline Instrument & Author(s) & School level \\
\hline LPCI: Lunar Phases Concept Inventory & Lindell \& Olsen [11]; & Middle school and College \\
& Lindell \& Sommer [12] & College \\
ADT2: Astronomy Diagnostic Test 2 & Zeilik [9]; Hufnagel [10] & College \\
LSCI: Light and Spectra Concept Inventory & Bardar et al. [13] & College \\
GECI: Greenhouse Effect Concept Inventory & Keller [14] & K-12 \\
ASSCI: Astronomy and Space Science Concept Inventory & Sadler et al. [15] & Middle school \\
CMPA: Comprehensive Moon Phases Assessment & Sherrod [16] & Middle school \\
CMPA-R: Comprehensive Moon Phases Assessment-Revised & Yetter et . [17] & College \\
ACI: Astronomy Concept Inventory & Bilici et al. [18] & College \\
SPCI: Star Properties Concept Inventory & Bailey et al. [19] & College \\
NGCI: Newtonian Gravity Concept Inventory & Williamson [20] & College \\
TOAST: Test Of Astronomy STandards & Slater [21] & College \\
ABI: Astronomy Beliefs Inventory & Favia et al. [22] & Kanli [23] \\
ACT: Astronomy Concept Test & Simon et al. [24] & High school and College \\
PFCI: Planet Formation Concept Inventory & & College \\
\hline \hline
\end{tabular}

are not always readily available. There are concept inventories in many fields, like the Force Concept Inventory in physics [6], the Chemical Concept Inventory in chemistry [7], the Biological Concept Instrument in life sciences [8], as well as the Astronomy Diagnostic Test in astronomy $[9,10]$, but most of these use a rather complex vocabulary, and test for concepts targeted at older adolescents (end of high school) and/or adults (college students, pre-service and in-service teachers, nonscience majors, etc.). A review of assessment tools developed specifically to measure knowledge in astronomy and/or about the phases of the moon found very few instruments adapted to younger students (see Table I).

Therefore, the present paper describes the development and validation of a new concept inventory about the phases of the moon (the Moon Phases Concept Inventory for Middle School, or MPCI-MS) targeting students 10 to 14 years old. The MPCI-MS addresses the many concepts and ideas that students should master when learning about lunar phases (i.e., the lunar phases concept domain). Prior research has shown that students have a variety of misconceptions about lunar phases, and that these ideas can interfere with their ability to develop a complete understanding of the topic [25-28]. It is hoped that this new tool can be used in middle school classrooms to assess the teaching of lunar phases, as well as in science education research to test new ways to teach this difficult astronomical concept. In the following sections, the existing assessment tools and concept inventories in astronomy that deal with lunar phases will be reviewed, and the reasons we chose not to use an already existing instrument, but to create a new one, will be exposed. Then, the development of the MPCI-MS, its validation process, and its psychometric properties will be described. Finally, we will conclude by proposing ways to improve the instrument.

\section{REVIEW OF INSTRUMENTS TO ASSESS KNOWLEDGE ABOUT LUNAR PHASES}

As mentioned above, several assessment tools are already available to evaluate knowledge possessed by students of different age groups about astronomical concepts (see Table I). Unfortunately, most of these are aimed at adults (college and university), are too complex to use with younger students, and/or do not target concepts related to lunar phases; they will not be reviewed here. There are five assessment tools listed in Table I that address the phases of the moon and target, or are close to targeting students aged 10 to 14 years old. One of the most popular and widely used concept inventories about lunar phases is Lindell and Olsen's Lunar Phases Concept Inventory (LPCI) [11,12]. Even though this instrument was designed for college-level students, there are examples of its use with middle school students (see Refs. [29,30]). Next is Sadler et al.'s Astronomy and Space Science Concept Inventory (ASSCI) [15], an instrument targeted at K-12 students. Unfortunately, this vast and comprehensive concept inventory contains only five questions about the phases of the moon, a number we consider insufficient to measure the whole breadth of knowledge necessary to understand the mechanism of lunar phases. Other instruments to consider are Sherrod's Comprehensive Moon Phases Assessment (CMPA) [16], Yetter et al.'s revised version of the CMPA (the CMPA-R) [17], and Kanli's Astronomy Concept Test (ACT) [23]. The latter, a 16-item instrument, was tested with 12th grade students, pre-service science teachers, and physics teachers, and contains very few questions about the phases of the moon. We consider that it targets too few lunar phases concepts, and that the language is too complex for the age group we are focused on. We review the CMPA, CMPA-R, and LPCI here. 
The CMPA is a 47 -item instrument (including six items for demographic purposes and one open-ended question) targeting upper elementary and middle school students, while the CMPA-R is a 31-item tool targeting the same grades and using questions similar to those found in the CMPA, although the CMPA-R contains several new questions about the global perspective on lunar phases (i.e., the aspect of the moon as seen from both hemispheres of the earth). Both instruments are based on a careful examination of the United States's state standards for middle school about the phases of the moon [16].

We have identified several issues with these two instruments. First, we found that the items in the CMPA and the CMPA-R were quite difficult for middle school children to understand, especially with regard to questions about the global perspective on lunar phases. This finding is confirmed by one of the authors of the CMPA-R, who wrote that "the reading level [of the CMPA-R] is about 5th grade; but it is still a rather difficult instrument for children" [31]. Another important issue with the CMPA and CMPA-R is the presence of items that contain hints or clues that could help respondents find answers to other items in the test, as this has the potential to skew the distribution of answers. For instance, items 12 and 15 in the CMPA-R (items 35 and 36 in the CMPA) show a polar view on the sun-earth-moon system. These items, and others, like item 21 of the CMPA-R, state that the moon orbits the earth; however, in item 16 of the CMPA-R, one proposed answer is "The moon does not move around the earth," which is clearly contradicted by statements in previous items, and is likely to be artificially less popular among respondents for this reason. Item 21 of the CMPA-R also mentions a duration of "one month" in relation to the moon's revolution around the earth, which is a clue to item 1 of the same instrument. In item 15 of the CMPA-R, one reads "If you were in a spaceship looking down on the earth's North or South Pole, in which position will the moon be located (a, b, c, or d) when we see a full moon on earth?"; the 2D polar view illustration accompanying the item can be confusing for younger students, since the sun, earth and moon appear to lie on the same plane (that of the page), and a respondent could be led to believe that the earth will cast a shadow on the moon at its full moon location (position $\mathrm{c}$ in the illustration), preventing him or her from choosing that particular answer to the question. Also, the earth casting a shadow on the moon is a common misconception to explain lunar phases (see Table S2 in the Supplemental Material [32] for a list of the most common misconceptions about the phases of the moon found in the literature). Item 22 of the CMPA-R states "If the moon is seen to change over several days in the Northern Hemisphere from a new moon to waxing crescent to first quarter to waxing gibbous to full moon, how will the moon be seen to change during the same time period in the Southern Hemisphere?" This clear description of the evolution of lunar phases from new moon to full moon ("waxing moon") is a direct clue to item 2 "When we see more of the illuminated portion of the moon today than we did yesterday, the moon is called a " (one choice answer is "waxing moon").

Finally, we found at least two incorrect or confusing statements in the CMPA: item 12 reads "When the sun reaches its highest point above the horizon from where you are standing, that point in the sky is known as the sun's...." with the target answer being "zenith"; later on, item 44 asks "When does a First Quarter moon reach its zenith?". In everyday language, the word "zenith" is sometimes used as a synonym for culminating point, but in astronomy, and all the more so in a teaching context, the zenith should be strictly defined as the point in the sky located directly overhead of an observer. It is quite possible for the sun and moon to reach the zenith in tropical zones, but for most respondents living at higher latitudes north or south of the tropics, item 12 is misleading, and risks strengthening the idea that the sun reaches the zenith every day at noon, which is a common misconception about the sun's apparent motion across the sky [33]. Item 44 would have made more sense if it asked instead "When does the first quarter moon reach its highest point in the sky?".

The LPCI is a 20-item multiple choice instrument (plus one confidence question and eight demographic questions) which assesses eight science and four spatial domains, all specifically related to lunar phases. It was originally designed to be used with college-level students, but several authors used it to measure learning gains about the phases of the moon with younger students, including middle school $[29,30]$. Despite this, we think that many of the same issues we identified in the CMPA and CMPA-R are also present in the LPCI when it comes to its use with students aged 10 to 14 years old. For instance, items 11, 16, and 19 of the LPCI show the same polar view on the moon's orbit, with the sun, earth and moon lying on the same plane, that can be confusing for younger children. Items 2 and 3 clearly state that the moon revolves around the earth; even though the knowledge that the moon revolves around the earth can probably be taken for granted with college students, it is not clear that middle school students know this for a fact, a crucial information the LPCI will miss in its inventory. Indeed, many misconceptions about lunar phases found in Table S2 (Supplemental Material [32]) can be linked to a misunderstanding (or ignorance) of the motion of the moon around earth, for instance, the idea that phases of the moon are due to the revolution of the sun around the earth and moon in $24 \mathrm{~h}$, found in children 11 to 12 years old [25]. Also, contrary to best practice for this type of instrument (See Sec. III B), the LPCI makes ample use of the "none of the above" or "all of the above" answers. There are also answers for the same items that diverge considerably in their length, as well as answers that combine previous propositions (i.e., "Both a and d," "Both $b$ and d," etc.). The reading level of the LPCI 
is also a concern for younger students; a rough examination of the reading level of some of the statements contained in the instrument put it at the secondary (high school) level, probably too high for children in middle school. Finally, for several questions in the LPCI, different phases of the moon are represented by white silhouettes in a black square, instead of using real photographs of the moon. This abstract representation can be problematic for younger students to associate with lunar phases, adding an unnecessary level of difficulty to the instrument. It is for these reasons that we decided to develop a new instrument to evaluate knowledge held by students 10 to14 years old about the phases of the moon, which we present in the following sections.

\section{DEVELOPING THE MOON PHASES CONCEPT INVENTORY FOR MIDDLE SCHOOL}

\section{A. Concept domain of the MPCI-MS}

The concept domain of the MPCI-MS is based on a detailed examination of the different notions, ideas, and concepts necessary to explain the mechanism of lunar phases. According to Brewer [34], the scientific model for lunar phases states that "the moon revolves around the earth and that the half of the moon facing the sun is always illuminated by the sun. On earth we see portions of the illuminated half and the portions [percentage] we see are determined by the relative positions of the earth, moon and sun" (p. 194). To understand the mechanism of lunar phases, one has to coordinate and combine several basic concepts, like the fact that the moon is a sphere, that it revolves around the earth, that it shines by reflecting light coming from the sun, that it's always half-illuminated and half-dark, etc. These ideas, which form the concept domain for lunar phases, are like bits of knowledge, or "atoms of understanding" about the moon, its physical and orbital characteristics, and the characteristics of the sun-earthmoon system, which one has to know and integrate into a working mental model in order to be able to understand the mechanism of lunar phases [35,36]. Using these basic ideas to form the lunar phases concept domain is the key to building an assessment tool that will measure the level of knowledge of every student with respect to the mechanism of lunar phases.

To determine the content of the concept domain of the MPCI-MS, the authors, both professional astronomers with research experience in the field, came up with a comprehensive list of statements about the moon, its physical and orbital characteristics, phases and eclipses, and the sunearth-moon system. A total of 67 statements related to the moon were created; statements directly related to the phenomenon of lunar phases were included, like "The moon doesn't produce its own light, but shines by reflecting light coming from the sun," as well as statements that have no link with the mechanism of lunar phases, like "Craters on the moon were created by asteroids and comets that hit the moon's surface," or "Unlike earth, the moon has no atmosphere or magnetic field." The complete list of 67 statements is in Table S1 (Supplemental Material [32]).

Next, the list of statements was submitted to seven professional astronomers in three Ph.D.-granting universities in Montréal and Québec City, Canada. These astronomers are all teaching Astronomy 101 (including the phases of the moon) in their respective institutions and are also active in research. They were asked to (i) check for any statement missing in the list and add any new statement that they felt was needed to describe the full mechanism of lunar phases; and (ii) indicate for each statement (original and new statements that they might have added) on a threepoint Likert scale how important they thought it was for the understanding of lunar phases. A three-point scale was chosen ("essential," "more or less necessary," and "unnecessary") in order to avoid excessive "spreading" in the decisions made by professional astronomers when judging each statement, thus forcing them to make a clear decision between statements that were essential and others that were less important. The scoring proceeded as follows: for each statement, the number of astronomers who checked essential, more or less necessary, and unnecessary were counted. All statements that received a clear majority of essential marks were retained. Ties were resolved by consensus. No new statement was added to the list, and 18 statements were considered essential by the majority of judges. They are listed in Table II. Statements that are similar to items found in the other instruments highlighted in Table I are also indicated.

\section{B. Item development}

One item for each of the 18 statements in the list shown in Table II was written. According to Mattheis and Nakayama [37], several criteria are important to consider when crafting items in a test: the items must represent a wide range of difficulty levels; the items must require an appropriate amount of reading and be at the appropriate reading level for the targeted age group; the items must be devoid of technical terms and scientific jargon that are not understood by children; and the length of the test must allow students to complete it in about 25 min or less. Towns [38] adds that multiple-choice answers should all be about the same length, be similar to each other, be clear of hints or clues that might lead to one of the proposed answers, and be arranged logically or alphabetically, so none of the possible answers stands out. The responses "all of the above" or "none of the above" should also be avoided. Krosnick and Presser [39] encourage the use of simple syntax, and warn against words and expressions with ambiguous meaning. They recommend that a questionnaire should "strive for wording that is specific and concrete (as opposed to general and abstract); make response options exhaustive and mutually exclusive; ask about one thing at a time (avoid double-barreled questions); and avoid questions with single 
TABLE II. List of 18 statements considered "Essential" by seven professional astronomers to understand the mechanism of lunar phases and forming the MPCI-MS concept domain. Items targeting similar lunar phases concepts in the CMPA, CMPA-R, LPCI, ASSCI, and ACT are indicated.

\begin{tabular}{|c|c|c|c|c|c|}
\hline Statement & CMPA & CMPA-R & LPCI & ASSCI & ACT \\
\hline $\begin{array}{l}\text { 1. The names of the major phases of the moon that can be seen from earth during one cycle } \\
\text { are (in chronological order): new moon, waxing crescent moon, first quarter moon, } \\
\text { waxing gibbous moon, full moon, waning gibbous moon, last quarter moon, waning } \\
\text { crescent moon. }\end{array}$ & $\sqrt{ }$ & $\sqrt{ }$ & $\sqrt{ }$ & & \\
\hline $\begin{array}{l}\text { 2. From earth, the moon can sometimes be visible during daytime, sometimes during } \\
\text { night-time, sometimes both. }\end{array}$ & $\sqrt{ }$ & $\sqrt{ }$ & $\sqrt{ }$ & & \\
\hline 3. As seen from earth, the moon rises and sets about 50 minutes later each day. & $\sqrt{ }$ & $\sqrt{ }$ & $\sqrt{ }$ & & \\
\hline $\begin{array}{l}\text { 4. As seen from earth, the visual aspect of the moon (i.e., its phase) changes from day to } \\
\text { day in a systematic and predictable manner. One can thus predict the future visual } \\
\text { aspect of the moon, i.e., its phase as seen from earth, based on its actual aspect or phase. }\end{array}$ & $\sqrt{ }$ & $\sqrt{ }$ & $\sqrt{ }$ & & \\
\hline $\begin{array}{l}\text { 5. As seen from earth, the same phases of the moon repeat about every } 29.5 \text { days. } \\
\text { 6. The moon is (very close to) a sphere. }\end{array}$ & $\sqrt{ }$ & $\sqrt{ }$ & $\sqrt{ }$ & $\sqrt{ }$ & $\sqrt{ }$ \\
\hline $\begin{array}{l}\text { 7. Lunar phases are caused by the changing fraction of the sunlit hemisphere of the moon } \\
\text { that is visible from earth due to the moon's orbital motion around our planet. }\end{array}$ & $\sqrt{ }$ & $\sqrt{ }$ & $\sqrt{ }$ & & \\
\hline $\begin{array}{l}\text { 8. There is always half the moon illuminated by the sun and half in the moon's } \\
\text { self-shadow. }\end{array}$ & $\sqrt{ }$ & & & & \\
\hline $\begin{array}{l}\text { 9. The moon doesn't produce its own light, but shines by reflecting light coming } \\
\text { from the sun. }\end{array}$ & $\sqrt{ }$ & $\sqrt{ }$ & & & $\sqrt{ }$ \\
\hline 10. The moon revolves around the earth. & & $\sqrt{ }$ & $\sqrt{ }$ & $\sqrt{ }$ & \\
\hline 11. The moon takes about 29.5 days to complete one revolution around the earth. & $\sqrt{ }$ & $\sqrt{ }$ & $\sqrt{ }$ & & \\
\hline $\begin{array}{l}\text { 12. The moon's diameter is about } 4 \text { times smaller than the earth's. The sun's diameter } \\
\text { is about } 110 \text { times larger than the earth's. }\end{array}$ & $\sqrt{ }$ & $\sqrt{ }$ & & & \\
\hline $\begin{array}{l}\text { 13. The distance between the earth and the moon is about } 400 \text { times smaller } \\
\text { than the distance between the earth and the sun. }\end{array}$ & $\sqrt{ }$ & $\sqrt{ }$ & & $\sqrt{ }$ & \\
\hline 14. From earth, the new moon is invisible in the sky. & $\sqrt{ }$ & $\sqrt{ }$ & $\sqrt{ }$ & & \\
\hline $\begin{array}{l}\text { 15. At any given time, the phase (i.e., visual aspect) of the moon is the same } \\
\text { for all observers located at the same latitude around the earth. }\end{array}$ & & & $\sqrt{ }$ & & \\
\hline $\begin{array}{l}\text { 16. At any given time, the phase of the earth as seen from the moon is always the reverse } \\
\text { (or complement) of the phase of the moon as seen from earth (i.e., new moon is full } \\
\text { earth, full moon is new earth, first quarter moon is last quarter earth, etc.). }\end{array}$ & & & & & \\
\hline $\begin{array}{l}\text { 17. As seen from earth, the moon moves eastward by about } 12 \text { degrees each day } \\
\text { with respect to the sun and background stars. }\end{array}$ & & $\sqrt{ }$ & & & \\
\hline $\begin{array}{l}\text { 18. As seen from earth, during waxing phases (i.e., from new moon to full moon), } \\
\text { the moon's elongation (i.e., the angle with the sun) increases from about } 0 \text { degree } \\
\text { to about } 180 \text { degrees; during waning phases (i.e., from full moon to new moon), } \\
\text { the moon's elongation decreases from about } 180 \text { degrees to about } 0 \text { degree. }\end{array}$ & & $\sqrt{ }$ & & & \\
\hline
\end{tabular}

or double negations" (p. 264). As for question order, the authors add that "early questions should be easy and pleasant to answer" (p. 264).

Similarly to most of the instruments listed in Table I, the distractors used as multiple-choice answers for most items in the MPCI-MS were based on a careful examination of past research on students' misconceptions about the lunar phases (see Table S2 in the Supplemental Material [32]). For each item, following recommendations of exhaustivity made by Krosnick and Presser [39], we attempted to propose as many answers as necessary to cover the most common misconceptions found in the literature, or to exhaust all possible answers a child could think of for any given situation described in the items. Hence, on occasion, we divert from best-practice advice to keep the number of choice answer to four or five, with the number of multiple-choice answers ranging from two to seven, numbers that are warranted for the sake of completion. Note that the LPCI has up to ten possible answers for several of its items.

Since the MPCI-MS is intended for middle school children, for which reading can still be difficult, the items were written in a style reminiscent of story books, with which children are already familiar, and accompanied with children's book-style illustrations (see Keely and Sneider [40] for several examples). Sixteen out of 18 items used a multiple-choice design, while one item used an association game, and another a true-or-false design. Figures 1-3 present examples of questions included in the MPCI-MS. 
1. The images on the left show the different phases of the Moon. The names of these phases are on the right, in random order. Using a line, connect each image to the name of the corresponding phase.

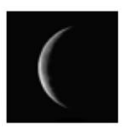

- First quarter

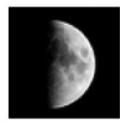

- Waning gibbous

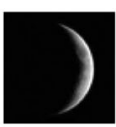

- New moon

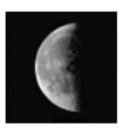

- Waning crescent

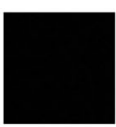

- Waxing gibbous

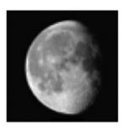

- Waxing crescent

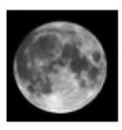

- Third quarter

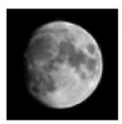

- Full moon

FIG. 1. Item 1 of the MPCI-MS: Association game between photos of lunar phases and their names.

The first version of the MPCI-MS was subjected to intensive scrutiny by the same professional astronomers that rated the list of statements in Table II, this time making sure that each question was representative of the statement it was associated with, that questions and answers were unambiguous, and that there was one, and only one, right answer for each item. The MPCIMS was then tested for readability in three 5th grade classrooms, assuming that if children in these classrooms could easily read and understand the items, older and more mature students targeted by the instrument would have no difficulty either. Students were asked to read each question first, and then one of the authors (P.C.) would have a group discussion with the whole class about what they understood the question to mean, if there was any word or
2. Read each statement below and indicate whether you think it is true or false. Circle the answer of your choice after each sentence.

\begin{tabular}{llll} 
& \multicolumn{2}{c}{ Your answer... } \\
You can see the Moon in the sky in the morning. & True & False \\
\hline You can see the Moon in the sky at noon. & True & False \\
\hline You can see the Moon in the sky in the afternoon. & True & False \\
\hline You can see the Moon in the sky in the evening. & True & False \\
\hline You can see the Moon in the sky at night. & True & False
\end{tabular}

FIG. 2. Item 2 of the MPCI-MS: True-or-false question about the visibility of the moon by day and by night.

expression that they didn't understand, and what they thought the right answer was, and why. Special care was taken to ask less talkative children to give their opinion as well. One school with a large number of non-native French learners (children of first-generation immigrants) was purposely visited to make sure that even children facing greater difficulties reading French would be able to cope with the wording of the items. Teachers were also consulted to obtain their opinion on the reading level of the items. Major and minor adjustments were made to several items after each visit, until there were no more adjustments necessary, and it was clear that children aged 10 to 11 years old (5th grade) and older would not find the MPCI-MS too difficult to read.

An evaluation of the readability index of each item was also performed using the online tool Scolarius ${ }^{1}$ [41], a free readability analysis tool in French that combines several well-known readability indexes: The Flesh Formula, The Gunning Formula or Fog Index, The Fry Formula, and The Easy Listening Formula (ELF). Scolarius analyzes the level of difficulty of a text according to the length of words, sentences, and paragraphs, allowing users to determine if the level of difficulty of a text corresponds to the level of understanding of the target audience, that is, middle school students in the case of the MPCI-MS. The result of this evaluation is presented in Table III.

All questions and answers listed in Table III have a reading level well below 80 (the cutoff for elementary reading level is 89 ), except for item 11 , which has a reading level of 83, still below the cutoff. In the case of item 11, the use of the conditional ("If the moon revolves around another celestial body, ...") lengthens and complexifies the sentence, which then raises the reading level by several points. However, the overall text for this question is very short, and students who took the test did not have any difficulty understanding it. Finally, after some more finetuning, the final version of the MPCI-MS was again submitted to the same seven professional astronomers as before, to make sure that no scientific error had been introduced during the revision process. No more changes

\footnotetext{
${ }^{1}$ Scolarius was developed by Influence Communication. For the time being, Scolarius is only available for texts in French.
} 


\section{Nora is looking at the calendar, which shows the phases of the Moon each month. She sees that the Moon will not be visible in the sky today. What do we call the phase of the Moon that we cannot see from the Earth? Circle the answer that best reflects what you believe.}
A. New moon.
B. First quarter.
C. Full moon.
D. Third quarter.
E. It is impossible to know.

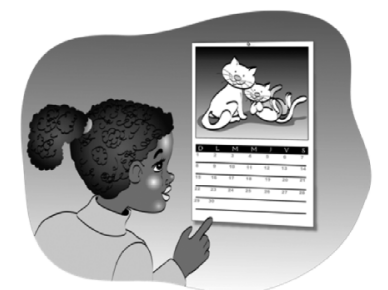

FIG. 3. Item 14 of the MPCI-MS: An example of a question written like a short story, with illustration.

were made to this version, which was then field tested with students aged 10 to 14 years old (see next section).

\section{VALIDATING THE MPCI-MS}

\section{A. Psychometric properties of the MPCI-MS}

Data were gathered with the MPCI-MS among the target group, i.e., students from 5th and 6th grade in elementary (middle) classrooms (aged 10 to 12 years old) and 1st and 2nd grades in secondary (high) schools (aged 12 to 14 years old). All students received the same paper version of the MPCI-MS, and recorded their answers directly onto the test by circling them. Students' scores were then recorded manually and double checked by at least two researchers and graduate students in education science. Classical test theory (CTT) was used to evaluate the psychometric

TABLE III. Reading level of 18 items and multiple-choice answers contained in the MPCI-MS as measured with the online tool Scolarius. Elementary reading level: 50-89; High school: 90-119.

\begin{tabular}{lcc}
\hline \hline Item & $\begin{array}{c}\text { Reading level } \\
\text { of the item }\end{array}$ & $\begin{array}{c}\text { Reading level of } \\
\text { multiple-choice answers }\end{array}$ \\
\hline 1 & 68 & 24 \\
2 & 73 & 46 \\
3 & 61 & 32 \\
4 & 70 & 48 \\
5 & 75 & 38 \\
6 & 69 & 43 \\
7 & 53 & 73 \\
8 & 79 & 56 \\
9 & 61 & 39 \\
10 & 60 & 55 \\
11 & 83 & 31 \\
12 & 69 & 26 \\
13 & 78 & 38 \\
14 & 74 & 21 \\
15 & 69 & 33 \\
16 & 65 & 65 \\
17 & 75 & 52 \\
18 & 69 & 58 \\
\hline \hline
\end{tabular}

properties of the MPCI-MS [42]: Cronbach's alpha coefficient $[43,44]$, a measure of reliability or internal consistency of a psychometric test; the level of difficulty $P$ (the percentage of correct answers per item, in other words a measure of how "easy" an item is) for each item in the pretest and post-test; and the point-biserial correlation $r_{\mathrm{pb}}$ for each item, i.e., the correlation between the answer given to a single item by one student and the total of correct answers obtained by this student to all items in the instrument. The point-biserial correlation coefficient, which is a special case of Pearson's correlation coefficient [45], quantifies the relationship between a continuous variable (the test score) and a variable that is a discrete dichotomy (the answer to a particular item of the test, which can be either 0 or 1, see Field [46]). For practical and cost-related reasons, a convenience sample composed of students from the metropolitan area of Montréal, Canada was selected after their teachers and parents agreed that they could participate in the research and signed the appropriate ethics approval form. The MPCI-MS was administered in 13 classrooms from grade 5 in primary schools to secondary 2 (2nd year) in high schools, to a total of 289 students $\left[M_{\text {age }}(\mathrm{SD})=10.2(0.3)\right.$ to $\left.14.1(0.2)\right]$. Table IV presents the demographics of our sample.

Most students in our sample answered the MPCI-MS twice in a test-retest setup, with or without teaching intervention about the lunar phases between administrations; a subset of two classes (5 and 8) answered the MPCIMS a third time as a delayed post-test two months after instruction. Three classes (7, 12 and 13) answered the MPCI-MS only once when we were testing administration procedures. For students who answered the MPCI-MS at least once as a pretest $(N=289)$, the average score on the MPCI-MS is $46.2 \%$ (standard deviation is $10.2 \%$ ), with the lowest score being $20.0 \%$ and the highest $80.0 \%$. As a posttest $(N=223)$, the average score on the MPCI-MS is $60.4 \%(\mathrm{SD}=15.8 \%)$ with the lowest score equal to $23.3 \%$ and the highest score equal to $100 \%$ (only one student reached maximum score on the post-test). As a delayed post-test $(N=34)$, average score is $65.7 \%(\mathrm{SD}=15.0 \%)$, lowest score is $26.7 \%$, and highest is $90.0 \%$. Figure 4 
TABLE IV. Demographic data for the 289 students who answered the MPCI-MS at least once (pretest). Post-test, delayed post-test, and teaching intervention (if any) for each class are also identified. "None" in the teaching intervention column indicates that students received no instruction whatsoever on lunar phases between the test's administration.

\begin{tabular}{|c|c|c|c|c|c|c|c|}
\hline $\begin{array}{l}\text { Class } \\
\text { number }\end{array}$ & Teacher & $\begin{array}{c}\text { School } \\
\text { level }\end{array}$ & $\begin{array}{c}\text { Mean } \\
\text { age }(\mathrm{SD})\end{array}$ & $N$ & $\begin{array}{c}\text { Post- } \\
\text { test }\end{array}$ & $\begin{array}{l}\text { Delayed } \\
\text { post-test }\end{array}$ & Teaching intervention \\
\hline 1 & Ms. M. G. and I. D. G. & 5 th & $10.2(0.3)$ & 23 & $\sqrt{ }$ & & None \\
\hline 2 & Ms. C. L. & 5 th & $10.5(0.3)$ & 22 & $\sqrt{ }$ & & $\begin{array}{c}\text { Textbook, exercise book } \\
\text { and videos }\end{array}$ \\
\hline 3 & Ms. J.-A. M. & 5 th & $10.5(0.5)$ & 24 & $\sqrt{ }$ & & Observation and modeling \\
\hline 4 & Ms. C. O. & 5 th & $10.5(0.3)$ & 21 & $\sqrt{ }$ & & Observation and modeling \\
\hline 5 & Ms. É. C. & 5 th-6th & $11.4(0.5)$ & 21 & $\sqrt{ }$ & $\sqrt{ }$ & Observation and modeling \\
\hline 6 & Ms. M. F. & 6th & $11.1(0.2)$ & 23 & $\sqrt{ }$ & & None \\
\hline 7 & Ms. S. P. & 6th & $11.3(0.3)$ & 23 & & & None \\
\hline 8 & Ms. J. R. & 6th & $11.8(0.4)$ & 13 & $\sqrt{ }$ & $\sqrt{ }$ & Observation and modeling \\
\hline 9 & Ms. I. P. & Sec. I & $13.1(0.3)$ & 26 & $\sqrt{ }$ & & Observation and modeling \\
\hline 10 & Ms. I. P. & Sec. I & $13.1(0.3)$ & 26 & $\sqrt{ }$ & & Observation and modeling \\
\hline 11 & Ms. I. P. & Sec. I & $13.2(0.3)$ & 24 & $\sqrt{ }$ & & Observation and modeling \\
\hline 12 & Ms. G. P. & Sec. I & $13.1(0.3)$ & 22 & & & None \\
\hline 13 & Ms. É. B. & Sec. II & $14.1(0.2)$ & 21 & & & None \\
\hline
\end{tabular}

presents a histogram of students' pretest and post-test scores on the MPCI-MS (delayed post-test score distribution is similar to post-test, but not shown). The distribution of all students' responses to individual questions on the MPCI-MS (pretest only) is presented in Table S3 (Supplemental Material [32]). A chi-square test for each item allowed the rejection of the null hypothesis that students' responses were randomly distributed: $\chi^{2}$ $(1, N=289)=10, p=0.002$.

The Cronbach alpha score is a measure of interitem correlations, and can be interpreted as a measure of how well a set of items measures a single construct. According to Kline [47], the generally accepted value of 0.8 for Cronbach's alpha is appropriate for cognitive tests, such as intelligence tests, whereas for ability tests and concept inventories, such as the MPCI-MS, a cutoff point of 0.7 is more suitable. The post-test Cronbach alpha score of the MPCI-MS $(N=223)$ is 0.780 , indicating a satisfactory

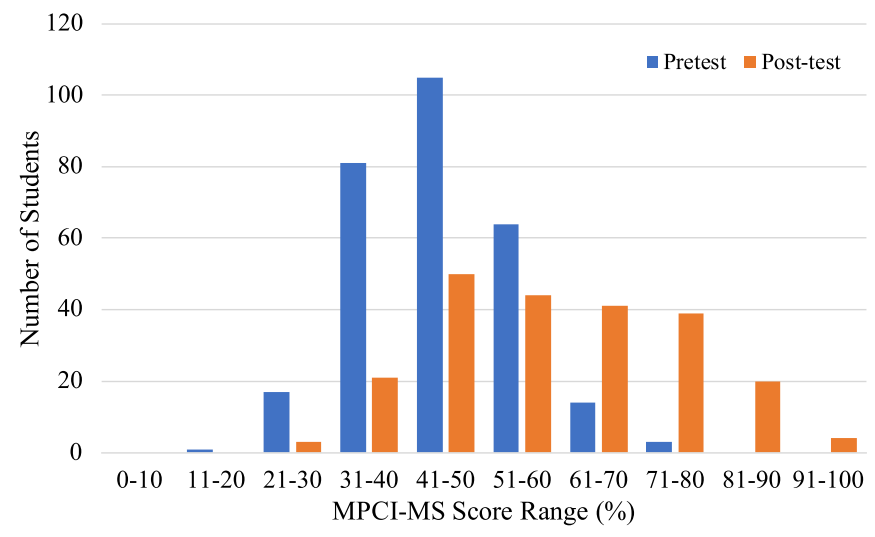

FIG. 4. Histogram of students' scores on the MPCI-MS, pretest $(N=289)$ and post-test $(N=223)$. interitem correlation; the MPCI-MS is thus a reliable instrument to measure 10 to 14 year-old students' knowledge about the lunar phases.

Item difficulty $P$ is related to the percentage of good answers for each item; it represents the proportion (or percentage) of students in a sample who answered an item correctly. Bardar et al. [13] and Simon et al. [24] suggest that the ideal interval for $P$ should be between 0.20 and 0.80, whereas Haladyna, Downing, and Rodriguez [48] propose the interval $0.30-0.90$; in this paper, we will be more conservative by using the $0.30-0.80$ interval. Finally, the point-biserial correlation, $r_{\mathrm{pb}}$, is the correlation between the answer to a single item given by one student and the total score obtained by the same student to all questions in the instrument. This discrimination index is used to quantify how an item differentiates between students who do well on a test and those who do poorly. Ideally, $r_{\mathrm{pb}}$ should be positive and larger than 0.20 [49], with an ideal range between 0.30 and 0.70 [50]. Table $\mathrm{V}$ presents the results of the psychometric analysis of the MPCI-MS.

In Table V, the $P$ index for the pretest ranges from 0.17 to 0.92 , with a mean $P=0.45$, and from 0.18 to 0.95 for the post-test, with a mean $P=0.58$; mean point-biserial correlation $r_{\mathrm{pb}}$ (post-test) is 0.359 , with a minimum of 0.066 and a maximum of 0.811 . Note that for item 1 , the association game between images of lunar phases and their names (see Fig. 1), individual answers are not independent, because the way a student answers part of the question narrows down the options left, increasing the probability of getting other parts of the question right or wrong. As a result, the probability of getting the next association correct or incorrect changes with every new association made. Association games are not usually found in a concept inventory, but we think it's an efficient way—and a fun way 
TABLE V. Item difficulty ( $P$, pretest and post-test) and pointbiserial correlation $\left(r_{\mathrm{pb}}\right.$, post-test) for each item in the MPCI-MS. For item 1, 2 and 12, the item difficulty is calculated on all subquestions combined, and the biserial correlation is reported.

\begin{tabular}{lccc}
\hline \hline Item & $\begin{array}{c}P \text { pretest } \\
(N=289)\end{array}$ & $\begin{array}{c}P \text { post-test } \\
(N=223)\end{array}$ & $\begin{array}{c}r_{\mathrm{pb}} \\
(N=223)\end{array}$ \\
\hline 1 & 0.35 & 0.55 & 0.811 \\
2 & 0.70 & 0.81 & 0.357 \\
3 & 0.25 & 0.61 & 0.481 \\
4 & 0.27 & 0.40 & 0.315 \\
5 & 0.68 & 0.74 & 0.459 \\
6 & 0.92 & 0.95 & 0.236 \\
7 & 0.47 & 0.65 & 0.361 \\
8 & 0.30 & 0.34 & 0.292 \\
9 & 0.59 & 0.86 & 0.352 \\
10 & 0.62 & 0.79 & 0.221 \\
11 & 0.17 & 0.45 & 0.449 \\
12 & 0.51 & 0.54 & 0.343 \\
13 & 0.28 & 0.36 & 0.313 \\
14 & 0.85 & 0.91 & 0.354 \\
15 & 0.20 & 0.18 & 0.066 \\
$16 *$ & 0.32 & 0.56 & 0.569 \\
$17^{*}$ & 0.30 & 0.35 & 0.273 \\
18 & 0.40 & 0.42 & 0.206 \\
\hline \hline
\end{tabular}

*After item 15 is removed (see Sec. IV B), these items are renumbered 15,16 , and 17 , respectively, in the final version of the MPCI-MS, available in the Supplemental Material [32].

for children - to demonstrate their mastery of an important aspect of the lunar phases concept domain, i.e., the nomenclature of phases. Thus, for item 1, our analysis is as follows: instead of reporting a difficulty level and point-biserial correlation for each of the eight subquestions, we calculated the percentage of correct answers for each student (pre- and post-test), and based our calculations of $P$ and of the biserial correlation on these numbers. We did the same with item 2 (see Fig. 2): even though each of the five true or false choices is independent, we again combined all subquestions in a single percentage of correct answers (pre- and post-test) and used these numbers to calculate $P$ and the biserial correlation reported in Table V. Item 12, with two subquestions, was treated the same way.

Ideally, students should achieve better results on the MPCI-MS after having received instruction on the topic of lunar phases. Accordingly, the difficulty index $P$ should be higher for all of the MPCI-MS post-test items compared to pretest scores (i.e., a larger proportion of students should have answered these items correctly after teaching). This is true for all items in the MPCI-MS, except for item 15, where $P$ is lower in the post-test (see Fig. 5). In terms of point biserial correlation $r_{\mathrm{pb}}$, only item 15 falls below the 0.20 cutoff (see Fig. 6). Even if we follow Simon et al. [24] and lower the point biserial correlation threshold to 2 standard deviations of $r_{\mathrm{pb}}\left[2 /(N-1)^{-1 / 2}=0.134\right.$ with

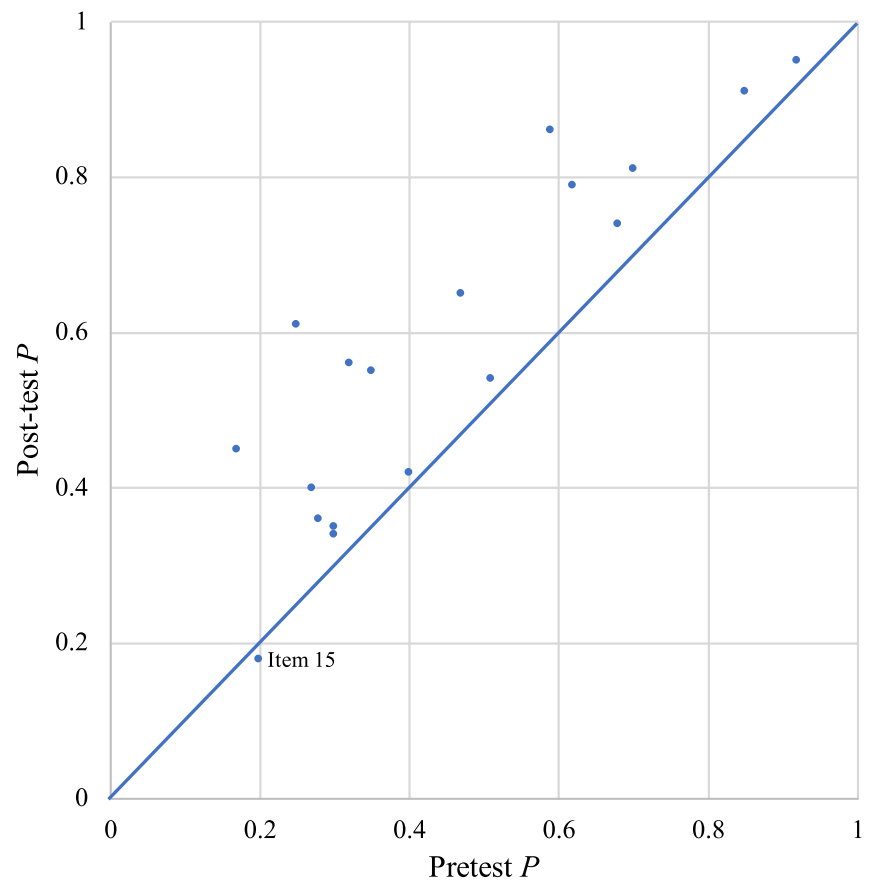

FIG. 5. Pretest item difficulty $(P)$ versus post-test, as reported in Table V. Item difficulty values are higher in the post-test for all items in the MPCI-MS (i.e., a larger number of students answered the items correctly), except for item 15, which lie below the diagonal line representing equal pre- and post-test difficulty.

$N=223$ ], this item remains problematic; it will be discussed below.

\section{B. Reviewing the items}

As is apparent by looking at Table V and Figs. 5 and 6, most items in the MPCI-MS have good psychometric properties overall: difficulty index $P$ is higher in the post-test and most point-biserial correlation coefficients fall in the 0.30 to 0.70 range; only one item has a $r_{\mathrm{pb}}$ value below 0.20 . The one exception is item 15 (aspect of a lunar phase as seen from different countries in the same hemisphere simultaneously) which is more problematic: it is very difficult ( $P$ goes from 0.20 to 0.18 from pretest to posttest) and its point-biserial correlation $r_{\mathrm{pb}}=0.066$ is well below the 0.134 cutoff. It seems that figuring out what the phase of the moon looks like as seen from two countries simultaneously is extremely difficult for most 10 to 14 year-old students, and that this question does not discriminate well between students. It is thus better to remove this item from the final version of the MPCI-MS. With item 15 removed (and items 16 to 18 renumbered 15 to 17; see Supplemental Material [32] for the final version of the instrument), the final Cronbach alpha score of the MPCI-MS becomes 0.786 , the pretest mean difficulty index becomes 0.47 , and 0.61 for the post-test; mean pointbiserial correlation becomes 0.376 . 


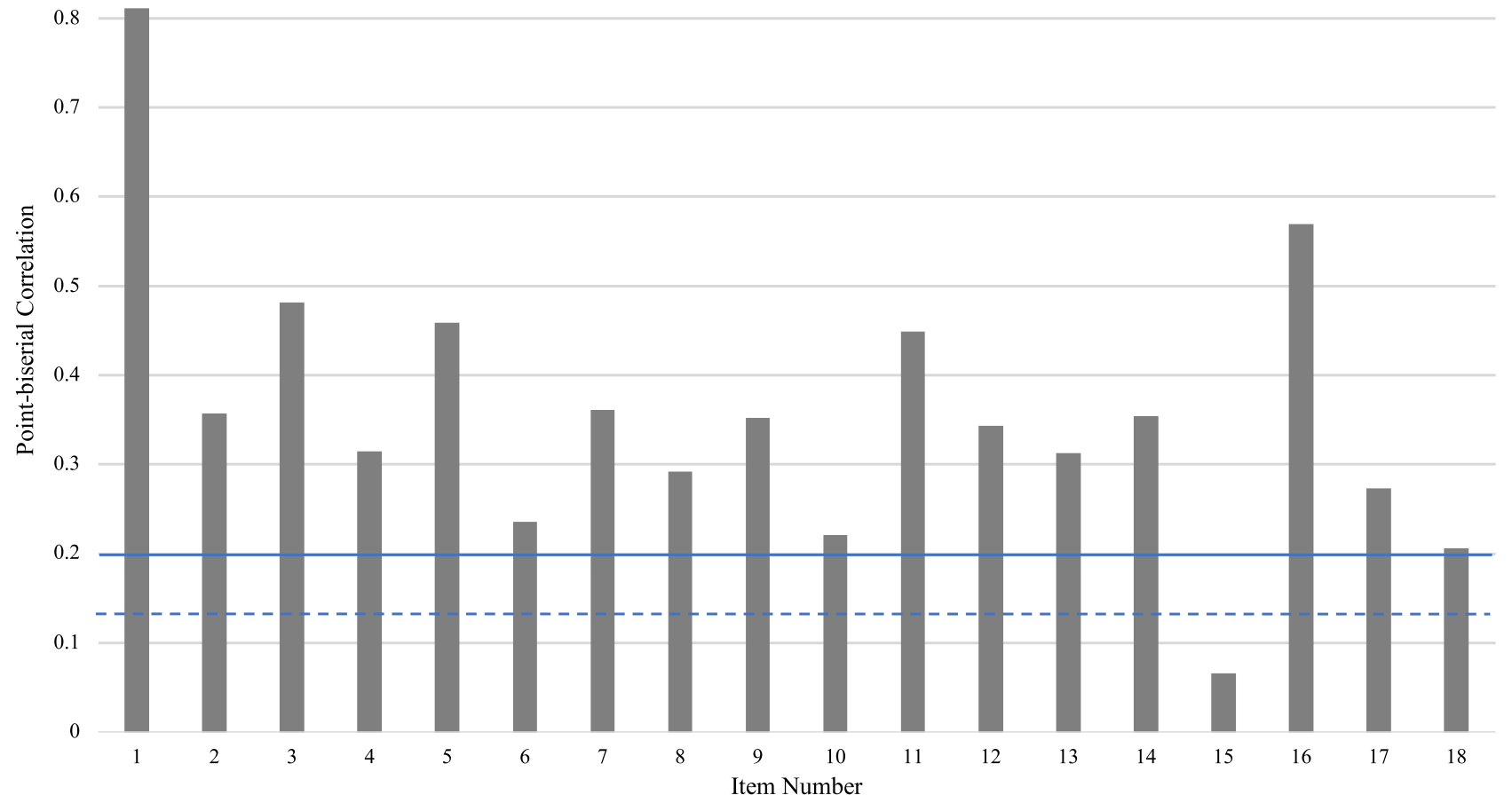

FIG. 6. Post-test item discrimination $\left(r_{\mathrm{pb}}, N=223\right)$. Ideal range for $r_{\mathrm{pb}}$ is between 0.30 and 0.70 , but values greater than 0.134 are still acceptable. The horizontal blue line is at $r_{\mathrm{pb}}=0.20$, while the dashed line is at $r_{\mathrm{pb}}=0.134$. Only item 15 falls below that line.

\section{Item validity}

Another aspect of the psychometric evaluation of a concept inventory is its validity, i.e., the characteristics of measured constructs and the way results can be interpreted [51]. In the case of a concept inventory, validity refers to how well the items in the instrument measure the scientific concepts targeted by the test [52]. With the MPCI-MS, students' understanding of the mechanism that causes the moon to show phases as seen from earth is the construct that could explain their performance on the test.

Content validity refers to the extent to which the test items are scientifically accurate, while face validity verifies how well the items represent the whole concept domain the instrument seeks to evaluate [24]. In other words, content validity checks that there are no scientific errors in the items, while face validity (completeness) promises that all relevant ideas related to the concept domain are covered by the test. Face validity of the MPCI-MS regarding the concept domain of lunar phases was already confirmed by the fact that the seven professional astronomers who ranked the 67 statements about the moon (Table S1 in Supplemental Material [32]) did not add any new statements, and agreed on the 18 statements necessary to represent basic ideas about lunar phases (i.e., the lunar phases concept domain). Content validity was also evaluated by experts: if the instrument has good content validity, experts should reach a perfect score on the test. To verify the MPCI-MS content validity, the final version of the instrument was submitted to four more professional astronomers (unrelated to the seven who scored the list of statements in Table S1 [32]), and they indeed obtained a perfect score, except for one who, after review, realized that he misread one question and checked his answer too fast. After correction, he too reached a score of $100 \%$.

Following Simon et al. [24] and Trochim's [53] recommendations, we also checked the concurrent validity of the MPCI-MS, i.e., the instrument's ability to distinguish between different populations of respondents. We ran an independent samples $t$ test comparing post-test scores of 5th graders $\left(N=45, M_{\text {score }}=16.8, \mathrm{SD}_{\text {score }}=4.7\right)$ and older students in the first year of high school $(N=76$, $M_{\text {score }}=20.3, \mathrm{SD}_{\text {score }}=3.8$ ), both samples having participated in the observation and modeling experiment. Results confirmed that the MPCI-MS was able to distinguish between the two groups (different by age and maturation): $t(119)=-4.379, p<0.001$. We also asked late elementary and early high school in-service teachers $\left(N=18, M_{\text {score }}=27.6, \mathrm{SD}_{\text {score }}=2.1\right)$, who participated in a two-day training seminar on lunar phases conducted by one of the authors (P.C.), to answer the MPCI-MS as a posttest, after observing the moon for a month and modeling the lunar phases (same treatment as 5th grade and secondary 1 students above). We compared their MPCI-MS post-test scores to those of high school students, using an independent samples $t$ test, and found a statistically significant 
difference between the two groups: $t(92)=-11.202$, $p<0.001$. Finally, we compared post-test results of all the students in the experimental group $(N=155$, $M_{\text {score }}=19.6, \mathrm{SD}_{\text {score }}=4.5$ ) with post-test scores of inservice teachers and again found a statistically significant difference: $t(171)=-13.157, p<0.001$. Interestingly, it appears that the MPCI-MS can also be used with adult inservice teachers with a minimum ceiling effect (only 4 out of 18 respondents had a perfect score on the post-test, none on the pretest). For the teachers who reached a perfect score after instruction, one could say that the training seminar turned them into experts on the mechanism of lunar phases, much like the professional astronomers who helped create the instrument and review its psychometric properties.

Finally, we checked the test-retest reliability of the instrument [49]: if a reliable test is administered twice at different times (not too far apart), to the same sample of students and in the same environmental conditions, then there should not be any significant difference between the test scores. Test-retest without instruction at one-week intervals with classes 1 and 6 shows no significant difference between the pretest and the post-test mean scores $\left[M_{\text {pre }}=13.696, M_{\text {post }}=14.523 ; t(45)=1.315, p=0.192\right]$, indicative of the high test-retest reliability of the MPCI-MS.

We thus conclude that the MPCI-MS is a valid and reliable instrument to measure knowledge about the concept domain of lunar phases with students aged 10 to 14 years old. The final version of the MPCI-MS (translated into English by the authors), without item 15, with items 16 to 18 renumbered 15 to 17 , and two new questions about eclipses added (items 18 and 19, see Sec. V) is available in the Supplemental Material [32]. This new numbering system will be used henceforth.

\section{DISCUSSION AND CONCLUSION}

Without assessment, learning cannot be measured and teaching cannot be improved. As the saying goes, we measure what we value and we value what we measure. Unfortunately, valid assessment tools about a particular topic, and tailored for a particular student age-group, are not always readily available, as was certainly the case with an assessment tool about the phases of the moon for younger children aged 10 to 14 years old. Because of several issues identified with other instruments about lunar phases targeting the same age group, like the LPCI, the ASSCI, the CMPA, the CMPA-R and the ACT (see Table I, Sec. II), this paper reported on the development and validation of a new concept inventory about lunar phases, the Moon Phases Concept Inventory for Middle School (MPCI-MS), a valid and reliable instrument to measure knowledge about the construct of lunar phases with students aged 10 to 14 years old. This new instrument can be used in realistic teaching situations, thus making it not only a practical research instrument to evaluate and compare teaching strategies, but also an easy-to-use assessment tool that can be readily utilized by teachers in their classrooms. Nonetheless, the MPCI-MS can definitely be improved and avenues to explore are presented below.

\section{A. Items about eclipses}

The items in the MPCI-MS are all based on a careful examination of the lunar phases concept domain, encompassing all the elements of the mechanism of lunar phases and the "bits of knowledge" that professional astronomers think students must possess in order to be able to understand the origin of the phenomena. In retrospect, though, it is possible that the criteria used to make the final decision about what statements to keep from the list in Table S1 (Supplemental Material [32]) may have been too tight, and one can wonder if it was wise to leave out from such a concept inventory items about eclipses of the sun and the moon, as these two phenomena are so closely linked with lunar phases. Eclipses occur because, in the moon's monthly journey around the earth which causes lunar phases, our satellite sometimes casts its shadow on part of our planet (solar eclipse), or travels through earth's shadow (lunar eclipse). Items about eclipses are indeed included in the LPCI, the ASSCI, the CMPA, the CMPA-R, and the ACT. When discussing with professional astronomers to draw up the final list of statements upon which items were based (see Table II, Sec. III), there were strong arguments in favor of asking questions about eclipses, but not enough in the end to retain them, especially since it was feared that the MPCI-MS would be too long to complete by students aged 10 to 14 years old. But now that the instrument has been trialed in several classrooms, and that the time it takes to fill it out was measured to be between 15 and $25 \mathrm{~min}$, which is quite acceptable, according to Mattheis and Nakayama [37], two new questions, one on lunar eclipses and one on solar eclipses, have been added to the MPCI-MS (see items 18 and 19 in the MPCI-MS in Supplemental Material [32]).

\section{B. Items 2 and 15}

Item 2 about the visibility of the moon during the day and at night is a series of statements that are either true or false; this item has very good psychometric properties. Item 15 in the final version of the MPCI-MS (was item 16 previously) about the possibility of seeing phases of the earth from the moon, has excellent psychometric properties as well, but only a two choice answer (Ann or Bob). For item statistics (discrimination and difficulty), it is best practice to have a minimum of three answer choices. Indeed, it is hard to assert the validity of a test item's discrimination if there are only two choices.

To improve these items, we suggest modifying item 2, asking students to choose among a series of four statements, only one being true: "The moon can only be seen at night"; "The moon can only be seen during the day"; 
"The moon can sometimes be seen at night, and sometimes during the day"; and "The moon can only be seen around sunrise and sunset". For item 15, we could add a third answer choice, which could read: "Candice: I don't think you can see the earth from the moon", and modify the illustration to include a third student. It is unlikely these modifications will profoundly change the psychometric properties of these two items, or that of the whole test, but it will make the MPCI-MS a better instrument overall.

\section{Limitations and future studies}

There are several limitations in the present study that need to be acknowledged, the first of which is the relatively small sample size of our study, which limits its generalizability. Second, although the MPCI-MS has good psychometric properties overall, there remain a few items (items $6,8,10,12,16$, and 17, these last two being items 17 and 18 in Table V) that either have a low point-biserial correlation index (below 0.30, typically), or show a very small increase in difficulty index between pre- and posttest. It could be that the wording of these questions is still difficult to understand, that the multiple-choice answers are confusing, or that the concepts targeted (i.e., the daily eastward motion of the moon among the stars for items 16 and 17) are too difficult for children 10 to14 years old. In the case of item 12, it seems that determining the size of the sun to scale with the earth represented by a basketball remains difficult, but it could also be because children do not have direct experience with the size of an actual hot-air balloon, or that such an object appears to be out of place in relation to the other objects in the list of possible answers. These items will need to be reevaluated to improve their psychometric properties, hence, new testing of the MPCIMS to overcome these limitations is planned. This revision process will offer the possibility to measure the psychometric properties of the two new items about eclipses that have been included in the final version (items 18 and 19), as well as the revised items 2 and 15.
Third, the instrument was developed in French, which makes it less useful outside French-speaking countries, and even though the MPCI-MS has already been translated into English (see Supplemental Material [32]), the English version will also need to be validated, and the instrument translated into other languages (Chinese, Spanish, etc.). Any offer to collaborate to that end will be welcome by the authors. Having the same concept inventory available in different languages would allow comparative studies to be conducted using the same instrument in different circumstances to test students' knowledge about the phases of the moon, a ubiquitous astronomical phenomenon that is easy to observe and which is present in most curriculums across the world, but remains difficult to teach and to learn.

Finally, even though the MPCI-MS can be used as a summative test at the end of a lesson on lunar phases, or as a pre- and post-test research instrument, it is also recommended that teachers and instructors use this instrument as a formative assessment tool, and analyze the pattern of answers given to each question individually, with the purpose of designing teaching interventions more directly targeting students' nonscientific ideas about the mechanism of lunar phases and the different aspects of the lunar phases concept domain.

\section{ACKNOWLEDGMENTS}

The authors wish to thank Ms. Alexandra Bolduc and Estelle Desjarlais for their help administering and scoring the MPCI-MS, as well as the many teachers that welcomed our research team in their classrooms. Thank you also to referees of the first draft of this paper for extremely helpful suggestions. This research was supported by a FRQSC Grant No. 2015-NP-180445, and a SSHRC Grant No. 4302016-00826, both to P.C. This research was approved by UQAM's Comité institutionnel d'éthique de la recherche avec des êtres humains [Institutional Committee for the Ethics of Research Involving Human Beings], certificate No. S_703437.
[1] W. K. Adams and C. E. Wieman, Development and validation of instruments to measure learning of expert-like thinking, Int. J. Sci. Educ. 33, 1289 (2011).

[2] Council of Ministers of Education, Canada, The common framework of science learning outcomes K to 12 (1997), retrieved from http://science.cmec.ca/framework/Pages/ english/table.html.

[3] National Research Council, A Framework for K-12 Science Education: Practices, Crosscutting Concepts, and Core Ideas (National Academies Press, Washington, DC, 2012).
[4] National Research Council, Next Generation Science Standards: For States, by States (National Academies Press, Washington, DC, 2013).

[5] S. Salimpour, S. Bartlett, M. T. Fitzgerald, D. H. McKinnon, K. R. Cutts, C. R. James, and A. Ortiz-Gil, The gateway science: A review of astronomy in the OECD school curricula, including China and South Africa, Res. Sci. Educ., https://doi.org/10.1007/s11165-020-09922-0 (2020).

[6] D. Hestenes, M. Wells, and G. Swackhamer, Force concept inventory, Phys. Teach. 30, 141 (1992). 
[7] D. R. Mulford and W. R. Robinson, An inventory for alternate conceptions among first-semester general chemistry students, J. Chem. Educ. 79, 739 (2002).

[8] M. W. Klymkowsky, S. M. Underwood, and K. R. Garvin-Doxas, Biological Concepts Instrument (BCI): A diagnostic tool for revealing student thinking, arXiv: 1012.4501 .

[9] M. Zeilik, Birth of the Astronomy Diagnostic Test: Prototest evolution, Astron. Educ. Rev. 1, 46 (2002).

[10] B. Hufnagel, Development of the Astronomy Diagnostic Test, Astron. Educ. Rev. 1, 47 (2002).

[11] R. S. Lindell and J. P. Olsen, Developing the Lunar Phases Concept Inventory, in Proceedings of the 2002 Physics Education Research Conference, Boise, ID (AIP, New York, 2002).

[12] R. S. Lindell and S. R. Sommer, Using the Lunar Phases Concept Inventory to investigate college students' preinstructional mental models of lunar phases, AIP Conf. Proc. 720, 73 (2004).

[13] E. M. Bardar, E. E. Prather, K. Brecher, and T. F. Slater, Development and validation of the light and spectroscopy concept inventory, Astron. Educ. Rev. 5, 103 (2006).

[14] J. M. Keller, Part I. Development of a concept inventory addressing students' beliefs and reasoning difficulties regarding the greenhouse effect, Part II. Distribution of chlorine measured by the Mars Odyssey gamma ray spectrometer, Ph.D. thesis, University of Arizona, 2006, retrieved from https://repository.arizona.edu/ handle/10150/193632.

[15] P. M. Sadler, H. Coyle, J. L. Miller, N. Cook-Smith, M. Dussault, and R. R. Gould, The Astronomy and Space Science Concept Inventory: Development and validation of assessment instruments aligned with the K-12 National Science Standards, Astron. Educ. Rev. 8 (2010).

[16] S. E. Sherrod, The development and validation of an assessment that measures middle school students' lunar phase understanding, Ph.D. thesis, Texas Tech University, 2009, https://doi.org/10.13140/RG.2.1.2159.3043.

[17] I. H. Yetter, K. K. Livengood, and W. S. Smith, State science standards and students' knowledge of what states value: Lunar phases, Electron. J. Sci. Educ. 21, 36 (2017), retrieved from https://ejse.southwestern.edu/article/view/16816.

[18] S. C. Bilici, F. O. Armagan, N. K. Cakir, and N. Yuruk, The development of an Astronomy Concept Inventory (ACI), Procedia Soc. Behav. Sci. 15, 2454 (2011).

[19] J. M. Bailey, B. Johnson, E. E. Prather, and T. F. Slater, Development and validation of the star properties concept inventory, Int. J. Sci. Educ. 34, 2257 (2012).

[20] K. E. Williamson, Development and calibration of a concept inventory to measure introductory college astronomy and physics students' understanding of Newtonian gravity, Ph.D. thesis, Montana State University, 2013, retrieved form https://scholarworks.montana.edu/xmlui/handle/1/3027.

[21] S. J. Slater, The development and validation of the Test of Astronomy STandards (TOAST), J. Astron. Earth Sci. Educ. 1, 1 (2014).

[22] A. Favia, N. F. Comins, and G. L. Thorpe, A direct examination of college student misconceptions in astronomy. II. Validity of the Astronomy Beliefs Inventory, J. Rev. Astron. Educ. Outr. 1, A3 (2015), retrieved from http://www
.toteachthestars.net/JRAEO/wp-content/uploads/2019/ 03/JRAEO003.pdf.

[23] U. Kanli, Using a two-tier test to analyse students' and teachers' alternative concepts in astronomy, Sci. Educ. Int. 26, 148 (2015).

[24] M. N. Simon, E. E. Prather, S. R. Buxner, and C. D. Impey, The development and validation of the Planet Formation Concept Inventory, Int. J. Sci. Educ. 41, 2448 (2019).

[25] J. G. Sharp, Children's astronomical beliefs: A preliminary study of year 6 children in south-west England, Int. J. Sci. Educ. 18, 685 (1996).

[26] L. L. Stahly, G. H. Krockover, and D. P. Shepardson, Third grade students' ideas about the lunar phases, J. Res. Sci. Teach. 36, 159 (1999).

[27] K. C. Trundle, R. K. Atwood, and J. E. Christopher, A longitudinal study of conceptual change: preservice elementary teachers' conceptions of moon phases, J. Res. Sci. Teach. 44, 303 (2007).

[28] K. C. Trundle, R. K. Atwood, and J. E. Christopher, Fourthgrade elementary students' conceptions of standards-based lunar concepts, Int. J. Sci. Educ. 29, 595 (2007).

[29] J. Wilhelm, Gender differences in lunar-related scientific and mathematical understandings, Int. J. Sci. Educ. 31, 2105 (2009).

[30] J. Wilhelm, M. Cole, C. Cohen, and R. S. Lindell, How middle level science teachers visualize and translate motion, scale, and geometric space of the Earth-Moon-Sun system with their students, Phys. Rev. Phys. Educ. Res. 14, 010150 (2018).

[31] W. Smith, personal communication.

[32] See Supplemental Material at http://link.aps.org/ supplemental/10.1103/PhysRevPhysEducRes.16.020107 for Tables S1-S3 and the English version of the MPCI-MS.

[33] J. D. Plummer, A Cross-age study of children's knowledge of apparent celestial motion, Int. J. Sci. Educ. 31, 1571 (2009).

[34] W. F. Brewer, Naïve theories of observational astronomy: Review, analysis, and theoretical implications, in International Handbook of Research on Conceptual Change, edited by S. Vosniadou (Routledge, New York, NY, 2008), pp. 155-204.

[35] A. Osterman Meyer, M. J. Mon, and S. T. Hibbard, The lunar phases project: A mental model-based observational project for undergraduate nonscience majors, Astron. Educ. Rev. 10 (2011).

[36] I. Taylor, M. Barker, and A. Jones, Promoting mental model building in astronomy education, Int. J. Sci. Educ. 25, 1205 (2003).

[37] F. E. Mattheis and G. Nakayama, Development of the Performance of Process Skills (POPS) test for middle grades students (1988), retrieved form https://files.eric.ed .gov/fulltext/ED305252.pdf.

[38] M. H. Towns, Guide to developing high-quality, reliable, and valid multiple-choice assessments, J. Chem. Educ. 91, 1426 (2014).

[39] J. A. Krosnick and S. Presser, Question and questionnaire design, in Handbook of Survey Research, 2nd ed., edited by J. D. Wright and P. V. Marsden (Emerald Group, West Yorkshire, UK, 2010), pp. 263-313. 
[40] P. Keeley and C. Sneider, Uncovering Student Ideas in Astronomy (NSTA Press, Arlington, VA, 2012).

[41] http://www.scolarius.com/.

[42] W. M. Schlingman, E. E. Prather, C. S. Wallace, A. L. Rudolph, and G. Brissenden, A classical test theory analysis of the light and spectroscopy concept inventory national study data set, Astron. Educ. Rev. 11, 010107 (2012).

[43] L. J. Cronbach, Essentials of Psychological Testing (Harper \& Row, New York, NY, 1949).

[44] L. J. Cronbach, Coefficient alpha and the internal structure of tests, Psychometrika 16, 297 (1951).

[45] D. Sheskin, Handbook of Parametric and Non-Parametric Statistical Procedures, 5th ed. (CRC Press, Boca Raton, FL, 2011).

[46] A. Field, Discovering Statistics using SPSS, 3rd ed. (Sage, London, UK, 2009).

[47] P. Kline, The Handbook of Psychological Testing, 2nd ed. (Routledge, London, 1999).
[48] T. Haladyna, S. Downing, and M. Rodriguez, A review of multiple-choice item-writing guidelines for classroom assessment, Appl. Meas. Educ. 15, 309 (2002).

[49] S. M. Brookhart and A. J. Nitko, Educational Assessment of Students, 8th ed. (Pearson, New York, NY, 2019).

[50] L. Ding and R. Beichner, Approaches to data analysis of multiple-choice questions, Phys. Rev. Phys. Educ. Res. 5, 020103 (2009).

[51] P. V. Engelhardt, An introduction to classical test theory as applied to conceptual multiple-choice tests, in Getting Started in PER (2009), retrieved from https://www.compadre.org/ Repository/document/ServeFile.cfm?ID=8807\&DocID= 1148.

[52] L. Crocker and J. Algina, Introduction to Classical and Modern Test Theory (Holt, New York, NY, 1986).

[53] W. M. K. Trochim, The Research Methods Knowledge Base, 2nd ed. (2006), retrieved form http://www .socialresearchmethods.net $/ \mathrm{kb} /$. 